\title{
Food web functioning of the benthopelagic community in a deep-sea seamount based on diet and stable isotope analyses
}

\author{
Preciado I. ${ }^{1}$, Cartes J. ${ }^{2}$, Punzón, A. ${ }^{1}$, Frutos, I., López-López, L. ${ }^{1}$, Serrano A. ${ }^{1}$
}

\author{
${ }^{1}$ Instituto Español de Oceanografía, Centro Oceanográfico de Santander. SPAIN \\ 2 Institut de Ciències del Mar de Barcelona, CSIC. SPAIN \\ 3 University of Hamburg, Centre of Natural History, Zoological Museum, Hamburg, Germany.
}

\section{INTRODUCTION}

Trophic interactions in the deep-sea fish community of the seamount Galicia Bank (NE Atlantic) was inferred by using stomach contents (SC) and stable isotope analyses (SIA) of 26 fish species and their main prey. Stableisotope-based estimates of trophic position provide a powerful fusion of trophic level and food web paradigms for evaluating trophic structure of marine food webs (Peterson and Fry, 1987; Post, 2002). To obtain the level of resolution required to discern complex trophic interactions, SIA analyses must be used in conjunction with other complementary information, such as direct diet analyses (Boyle et al 2012).

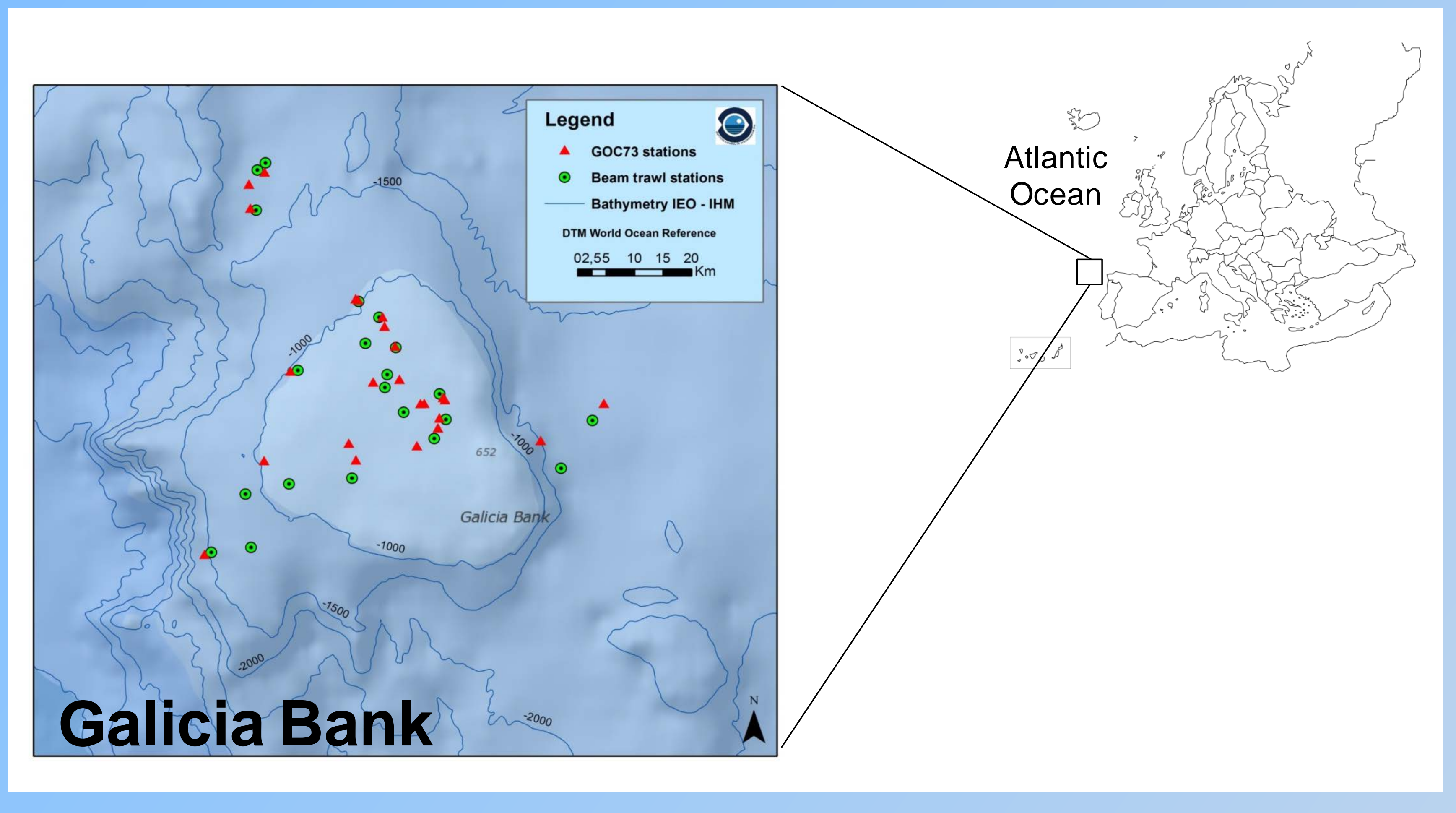

\section{MATERIAL AND METHODS}

Three surveys were carried out in summers' 2009, 2010 and 2011, between 625 and 1800 m depth. Faunistic compartments were sampled using GOC73 (megabenthic fauna) and beam trawl (epibenthic assemblages). Specimens from each station were sorted by species and identified to species level. A total of 26 fish species were dissected and stomach contents analysed. Only fish species with at least 10 full stomachs were used in the multivariate analyses (11 fish species). To identify trophic guilds based on diet composition, quantitative differences between the 11 fish species were addressed by multidimensional scaling (MDS)

SIA analyses were also performed in 23 predators and 10 prey. To estimate the trophic level $(\mathrm{TL})$ of predators, Phronima sedentaria was used as baseline $(\mathrm{TL}=2)$

RESULTS

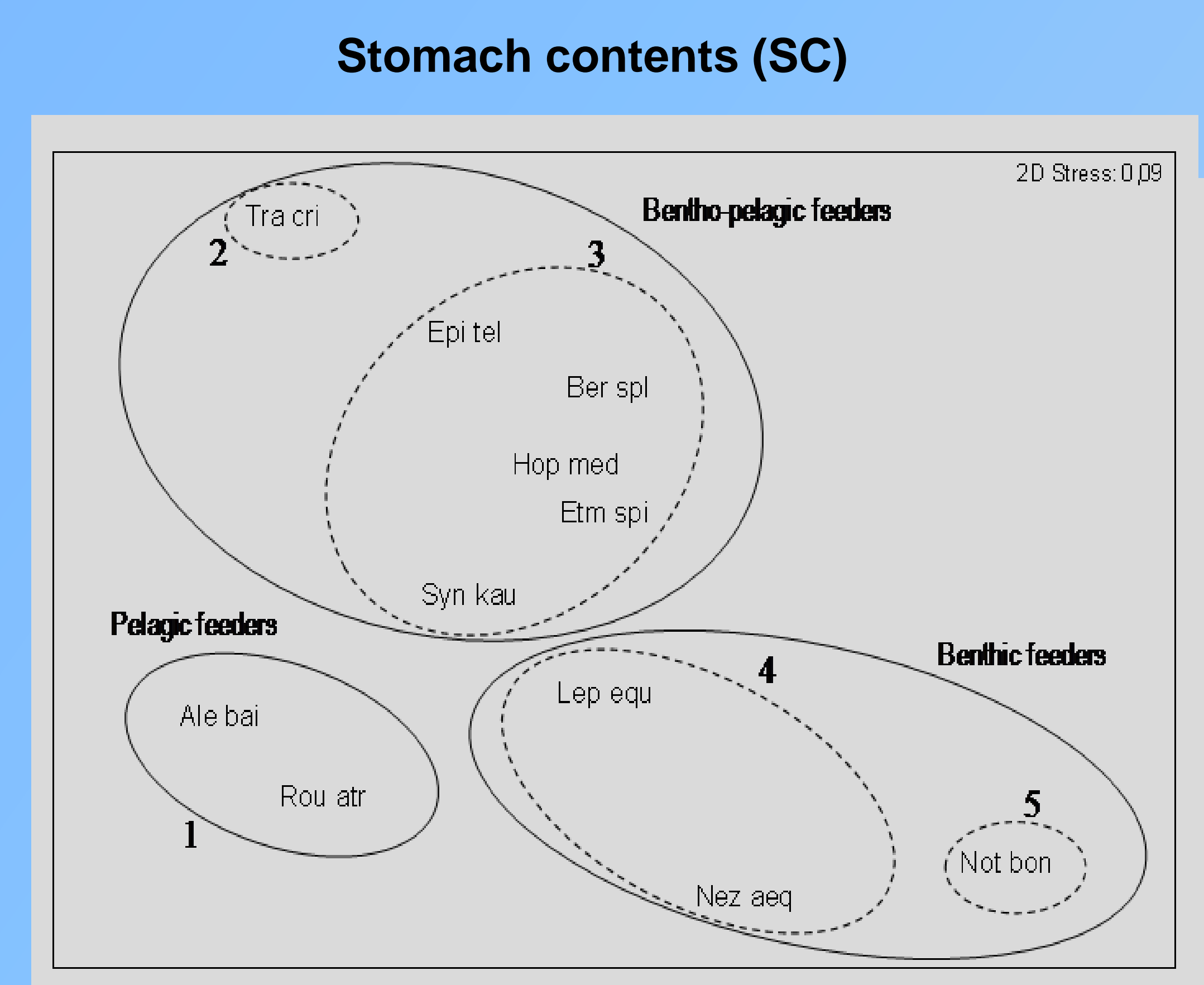

Three main trophic guilds were identified: i) pelagic feeders, ii) bentho-pelagic feeders and iii) benthic feeders.
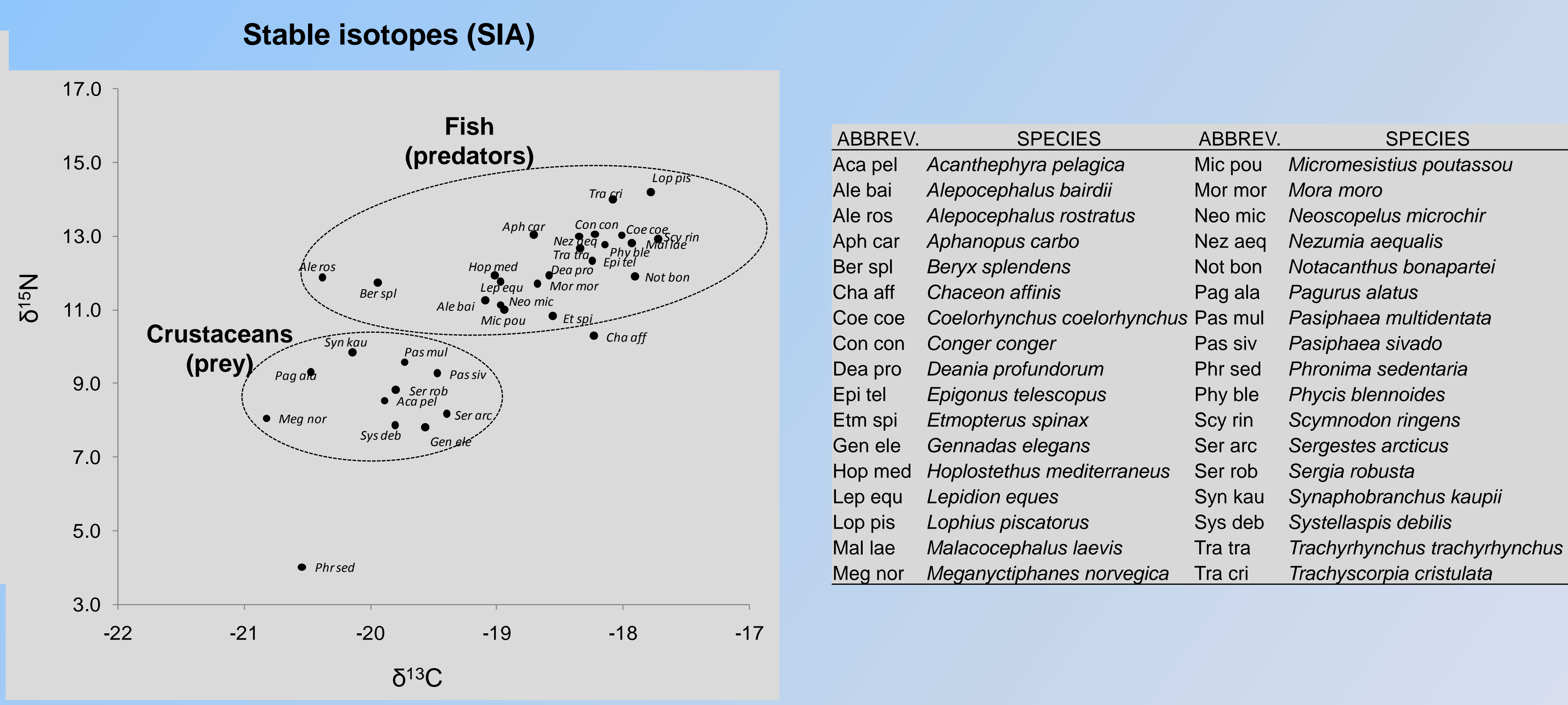

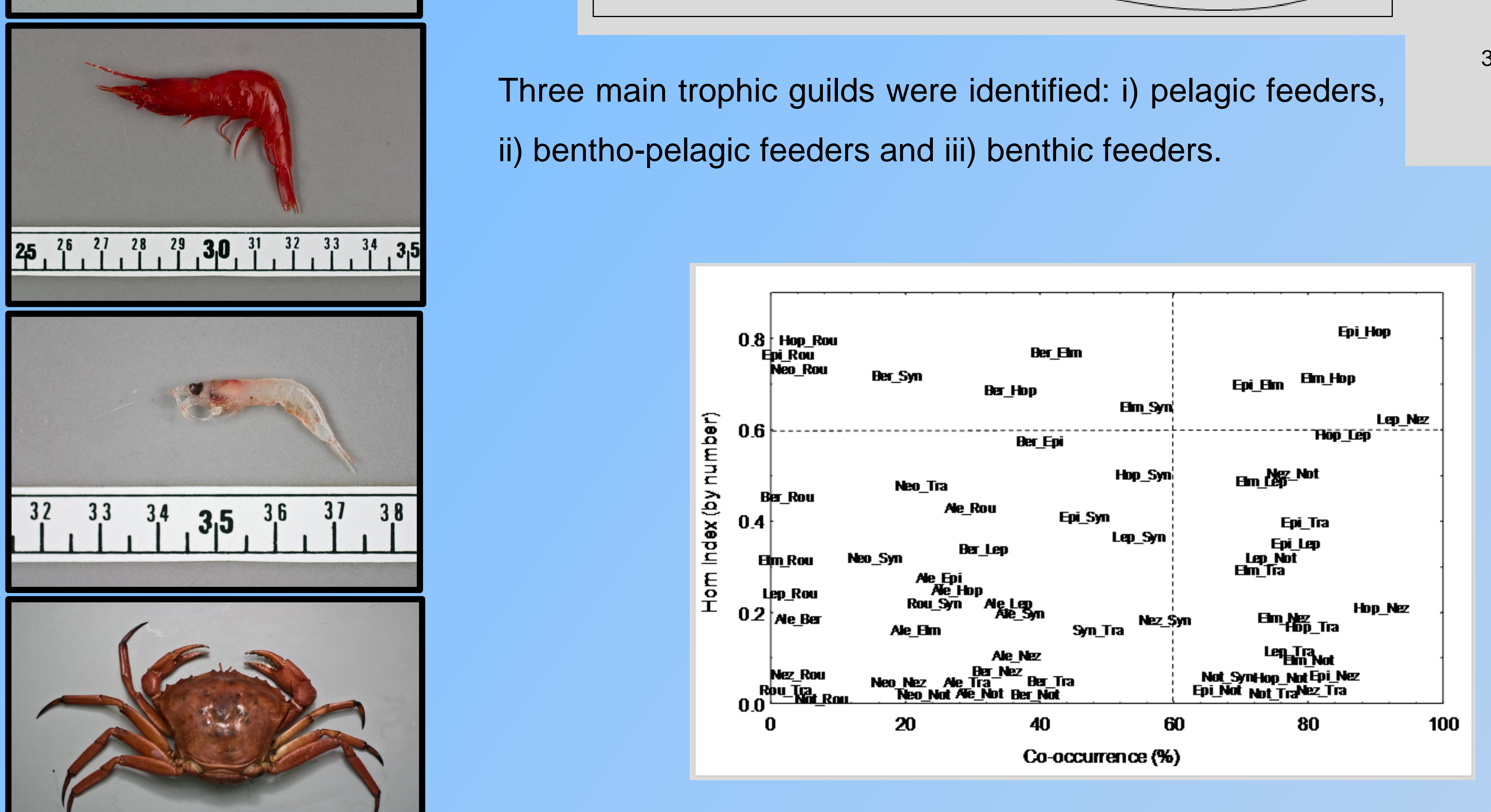

High potential competition for food was observed between two benthic feeders ( $N$. aequalis and $L$. eques), and three benthopelagic feeders (E. telescopus, $H$. mediterraneus and $E$. spinax)
According to SIA analyses Lophius piscatorius and Trachyscorpia cristulata constitute the top-predators in the benthopelagic food web of Galicia Bank. Fish and crustaceans appeared split into two welldistinguished groups, reflecting predator-prey relationships (1 TL).

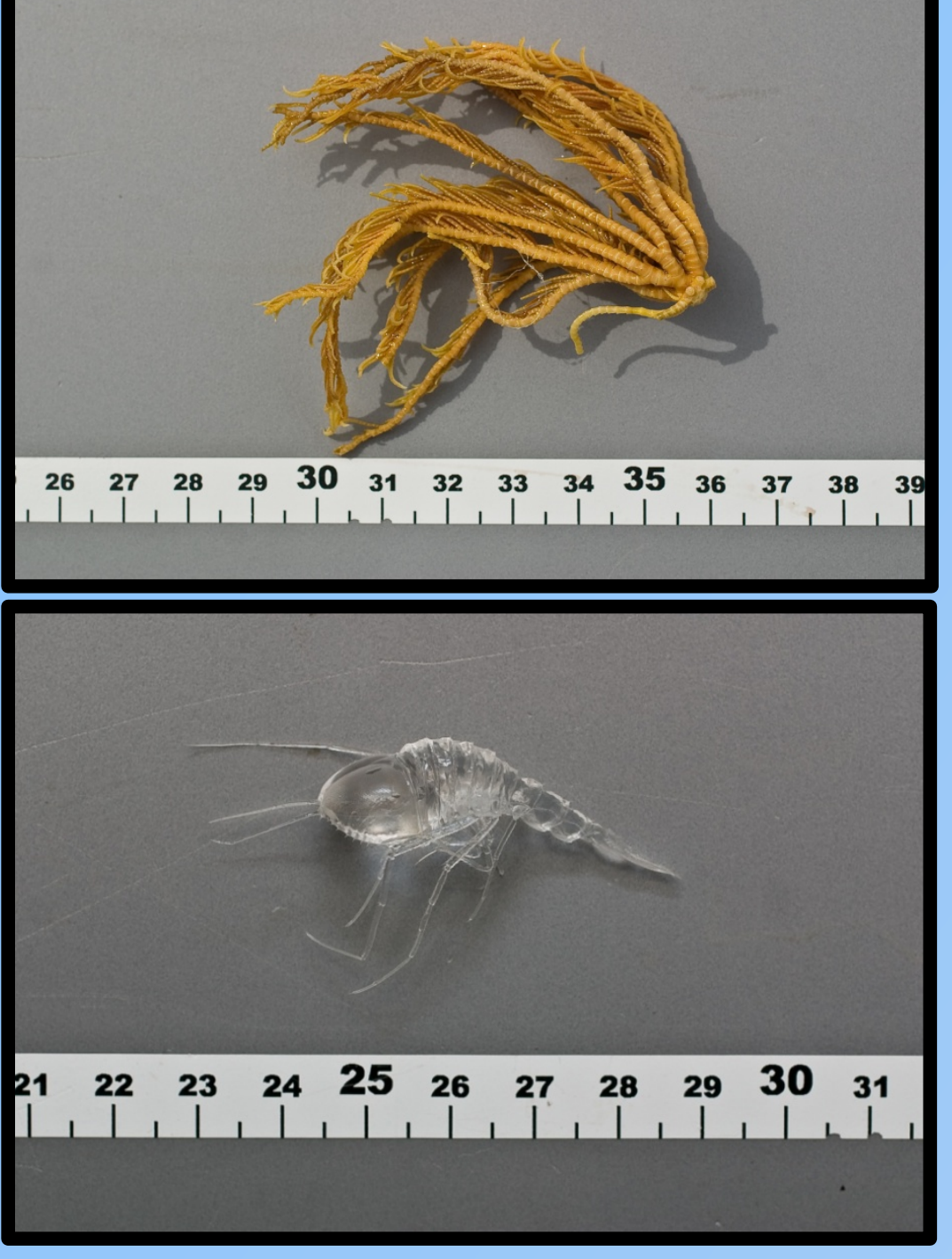

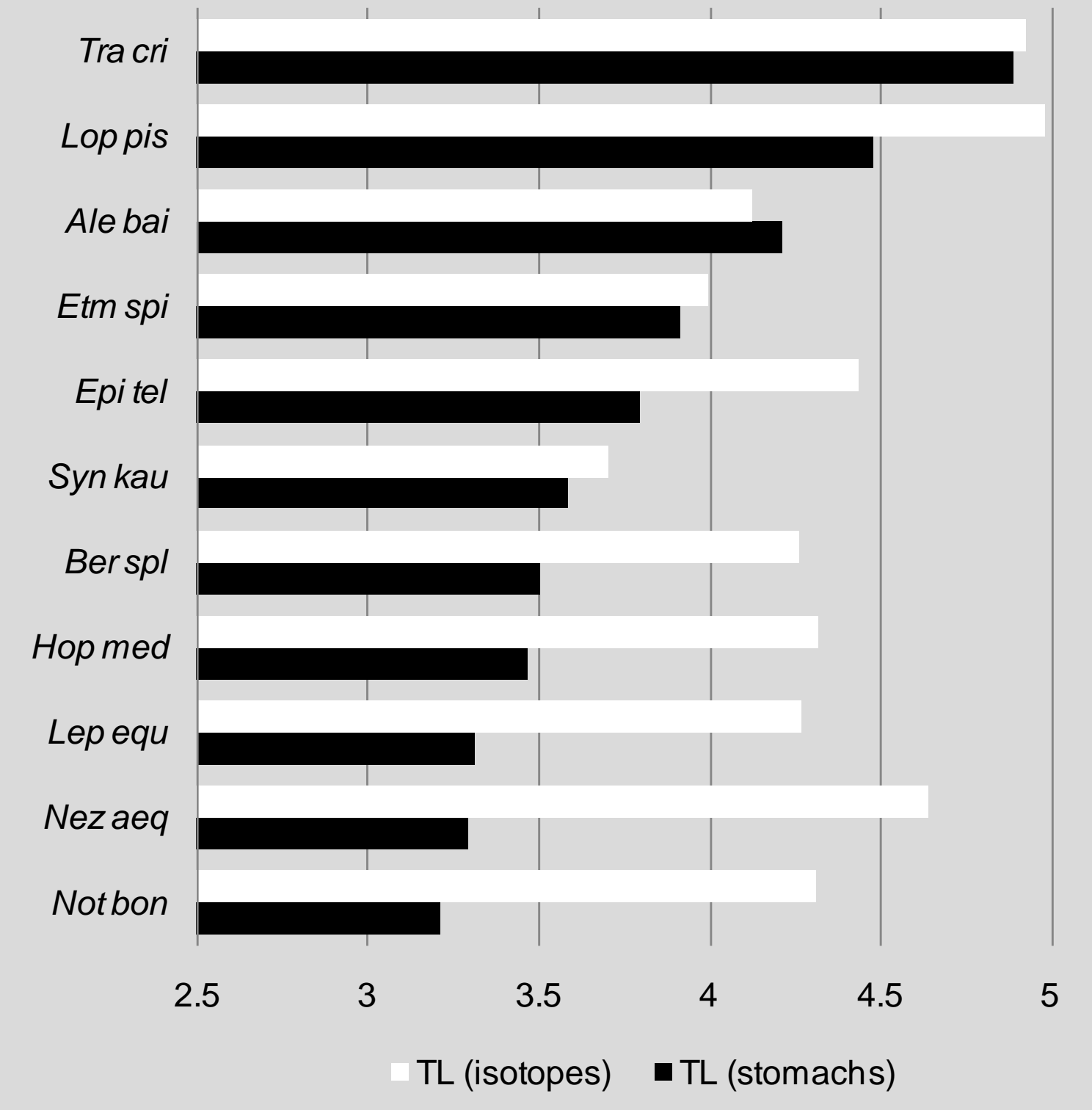

Trophic level estimations based on stable isotope analyses (SIA) were always higher than that based on stomach contents, except for the species Alepocephalus bairdii.

\section{CONCLUSIONS}

During summer, functioning of benthopelagic food web in Galicia Bank are more influenced by communities dwelling the water column than by deep-sea benthos. Vertical migrating benthopelagic shrimps and macro-zooplankton, mainly euphausiids and mysids, were identified to play a key role in the Galicia Bank food webs, unlike benthic fauna which was found as a pauperized compartment. However, according to SIA analyses, benthic component appeared to gain importance in previous months. These results demonstrate that both approaches, SC (snapshot of diet) and SIA (assimilated food), provide complementary views of food web functioning and dynamics in different seasons. 